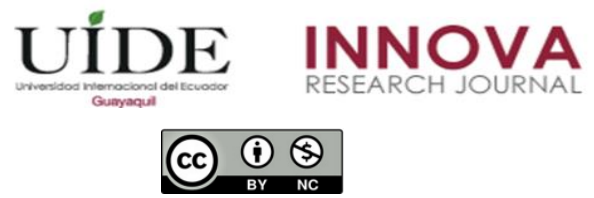

INNOVA Research Journal, ISSN 2477-9024

(Septiembre-Diciembre 2020). Vol. 5, No.3.1 pp. 201-215

DOI: https://doi.org/10.33890/innova.v5.n3.1.2020.1530

URL: http://revistas.uide.edu.ec/index.php/innova/index

Correo: innova@uide.edu.ec

\title{
La Sinergasia y nuevos emprendimientos innovadores durante la pandemia del Covid 19 en Ecuador, primer semestre de 2020
}

\section{The Sinergasia and new innovative ventures during the Covid 19 pandemic in Ecuador, first half of 2020}

\author{
María Augusta Játiva Pesantez \\ (1) https://orcid.org/0000-0001-6290-8901 \\ Universidad Internacional del Ecuador \\ Jaime Leopoldo Cabezas Maldonado \\ (D) https://orcid.org/0000-0003-2503-0567 \\ Investigador independiente, Ecuador
}

Autor para correspondencia: mjativa@uide.edu.ec; jaimecabezas58@hotmail.com

Fecha de recepción: 13 de septiembre de 2020 - Fecha de aceptación: 16 de noviembre de 2020

\section{Resumen}

Esta investigación bibliográfica e histórica tiene como objeto encontrar el estado del arte de la teoría de la Sinergasia, ciencia que estudia la cooperación y asociación humana, como una teoría praxeológica de la firma; una entidad empresarial formada al menos por dos individuos, término acuñado por el Doctor Leonardo Ravier en el marco de la Escuela Austriaca de Economía y como la aplicación axiomática de diez principios en los que se fundamenta esta teoría, sirve de explicación de hechos históricos de la empresarialidad y que los observamos en la creación de los nuevos emprendimientos y aplicaciones innovadoras durante el primer semestre del año 2020 en los que el mundo entero en general y el Ecuador en particular se ha visto abocado a una situación de destrucción del ingreso (y producto) de los individuos, debido a la caída del empleo, como resultado de la Pandemia de la enfermedad conocida como COVID 19. Hemos observado por tanto la creación de nuevas modalidades de negocios y actividades productivas, como resultado de la urgente necesidad de adecuarse casos proactivamente a la nueva realidad; de cualquier manera, desde la perspectiva de la empresarialidad con resiliencia, una actitud creativa se ha hecho presente en el mundo de los negocios y se lo ha podido observar durante estos primeros seis meses del año 2020, a pesar de las restricciones impuestas por el Estado.

Palabras claves: Sinergasia; emprendimiento; conocimiento empresarial; firma.

\begin{abstract}
This bibliographical and historical research aims to find the state of the art of the theory of Synergy, (a science that studies human cooperation and association, as a praxeological theory of the firm; a business entity formed by at least two individuals). by Doctor Leonardo Ravier in the framework of the Austrian School of Economics and as the axiomatic application of ten principles on which this theory is based, serves as an explanation of historical facts of entrepreneurship and that we
\end{abstract}


observe them in the creation of new ventures and applications innovations during the first semester of 2020 in which the whole world in general and Ecuador in particular has been doomed to a situation of destruction of income (and product) of individuals, due to the fall in employment, as a result of the Pandemic of the disease known as COVID 19.

We have therefore observed the creation of new business modalities and productive activities, as a result of the urgent need to proactively adapt cases to the new reality; In any case, from the perspective of resilience entrepreneurship, a creative attitude has been present in the business world and has been observed during these first six months of 2020, despite the restrictions imposed by the State.

Keywords: Sinergasia; entrepreneurship; business knowledge; firm.

\section{Introducción}

Este resultado es parte de una investigación mayor cuya finalidad pretende encontrar explicaciones para los actos creativos y coordinadores de los emprendimientos, en la ciencia de la acción humana o praxeología (Mises, 2011), además en la teoría de la eficiencia dinámica (Huerta de Soto, 2004, 2014) y finalmente en la teoría praxeológica de la firma (Ravier, 2016), llamada sinergasia como una ciencia que estudia la cooperación y asociación humana; de ahí que su expresión institucional, la firma, una entidad empresarial formada al menos por dos individuos que cooperan y coordinan entre sí con el objeto de alcanzar similares fines que conjuntamente consideran valiosos, usan los medios más útiles, descubren cómo resolver la escasez de los mismos mediante creatividad e innovación, usando el conocimiento práctico, tácito y disperso (Hayek, 1997), al menos de estas dos seres humanos o más personas que se unen alrededor de un emprendimiento, dando lugar a la firma, para alcanzar la meta deseada, lo que les traerá el éxito o el fracaso, el que es medido mediante cálculo económico, contable, financiero.

Estas acciones toman un tiempo empresarial único, que va desde la formulación de un plan que se lo ejecuta, todo en un ambiente de instituciones, que en la medida que presentan el mayor grado de respeto a la libertad del individuo, permite potenciar el éxito de la firma y el carácter innovador de sus productos, sean bienes o servicios, adecuados a las circunstancias las que han sorteado los obstáculos propios de la ignorancia, mediante una genuina creatividad. Toda firma, como forma empresarial asociativa, se desenvuelve en un entorno de incertidumbre inerradicable, que solo encontrará seguridad en la medida en que instituciones estables y respetadas como el derecho, el lenguaje, la moneda, el mercado como proceso, den un entorno predecible para emprender; serán mejores aquellas instituciones menos penetradas por las actividades interventoras y descoordinadoras del Estado y de su poder de coacción y violencia. (González, 2014), (Huerta de Soto, 2010).

\section{Fundamentación Teórica}

La escuela austríaca de economía es diferente del marxismo y de la síntesis neoclásica keynesiana o mainstream de la Ciencia Económica; enfoques teóricos incompletos e inmorales a los que la escuela austriaca los califica de cientismo, como lo ha señalado Huerta de Soto (2016): 
Siguiendo a Hayek, denominaremos cientismo a la indiscriminada e indebida aplicación del método de las ciencias naturales al campo de las ciencias sociales o de la acción humana. Puede interpretarse que el cientismo tiene diversas razones de ser, entre las que se han mencionado al complejo de inferioridad de los científicos sociales, que tradicionalmente han deseado alcanzar la misma precisión, en cuanto a predicciones y resultados, que sus colegas de las ciencias de la naturaleza, elaborando una ingeniería social que permitiera solucionar todos los problemas sociales y respondiendo así a unas demandas sociales que, hasta ahora, se han considerado legítimas y justificadas. También, hemos mencionado... () Cómo el cientismo en el campo social tiene su origen en una mala copia de los posicionamientos de la física desarrollada en los últimos dos siglos.

Los enfoques cientistas, impregnados en las ciencias sociales desde fines del siglo XIX se basan en un método matemático por tanto reduccionista, objetivista, empirista, resultado de lo cual se acepta como dada la riqueza y la pobreza, por tanto, la separación del ser humano que adelanta capital, maquinaria, equipo, del ser humano que trabaja. Ese método hipotético deductivo con un par de modelos de eficiencia estáticos, llamados competencia perfecta o monopolio, con un enfoque mecanicista propio de la física (química y biología, es decir los métodos experimentales de las ciencias naturales) y no de la praxeología o estudio de la acción humana, establece mecánicamente que, para alcanzar un bienestar estático, es necesaria la mal llamada justicia redistributiva.

Incluso el marxismo en su enfoque parte de la doctrina de la lucha de clases (Lenin, s/f) como algo determinado por unas leyes objetivas que están fuera de la conciencia de los seres humanos o en el caso de la síntesis neoclásica - keynesiana, como una corriente dominante y generalizada que promueve las políticas interventoras, por tanto descoordinadoras, al hacer del uso de la fuerza y la violencia del Estado (Nozick, 1991), mediante gasto público y despilfarro, financiado con cargas impositivas lesivas, con las cuales se apropian de un alto porcentaje de la renta o producto generado en su acto empresarial, por cada individuo de la población económicamente activa.

Al respecto encontramos en los trabajos de Cabezas (2017) y Cabezas y Vázquez (2017) sobre la falla del Estado y el error tan popularmente aceptado de mezclar desigualdad con pobreza, términos antónimos, algunas conclusiones: que mientras más grande es el gasto del Estado (medido normalmente en porcentaje del PIB), más grande es la posibilidad de corrupción, violencia y por tanto de pérdidas de eficiencia; o que hay que repartir la riqueza para igualar ingresos y patrimonios. Hay que estar claro en lo siguiente: excepto por la igualdad ante la ley, en la vida real nadie es igual a nadie, ni físicamente, peor mentalmente, de ahí la necesaria división del conocimiento que hace posible la especialización de cada ser humano.

La escuela austriaca de economía, es una aliada firme del derecho natural que parte de principios fundamentales como derecho a la vida, derecho a la propiedad y derecho a la libertad, partiendo de ideas originales como la libertad en un sentido de un derecho negativo y que siguiendo a Hayek (1996) y Ayau (2002) se define como "libertad es la ausencia de coacción arbitraria", o como bien lo manifestó Benegas Lynch (1986) "Libertad es el respeto irrestricto al proyecto de vida ajeno", según lo cual cada individuo es libre de elegir (Friedman, 1983) y llevar adelante su proyecto de vida sin el menoscabo por parte de nadie de poder coartar esa 
posibilidad, acción que la ejerce responsablemente, respetando el derecho de otros a llevar de la misma manera adelante sus propios proyectos de vida.

Es necesario anotar que los otros supuestos derechos promovidos por el estado del bienestar y que tomó forma en la declaración de los derechos humanos promovidos por las Naciones Unidas (1948) o reescritas, corregidas y exageradas en nuestra Constitución del Ecuador (2008), no son sino "anhelos" que se los pretende alcanzar a costa de políticas redistributivas por medio de la violencia estatal, sustentada en las teorías del maistream. Es decir, tener acceso gratuito o subvencionado a una inmensa cantidad de bienes y servicios como que fueran derechos (la educación, la salud, la vivienda, la alimentación, el agua, el aire puro, etc.), lo cual ha sido la patente de corso para promover toda clase de políticas redistributivas basadas en la expoliación y expropiación del producto o ingreso del trabajo ajeno, impuestos, es decir de la empresarialidad en proporciones que llegan muchas veces hasta el cincuenta por ciento de la renta.

A su vez parafraseando a Huerta de Soto (2014), quien ha explicado la teoría de la eficiencia dinámica de la siguiente manera como una consecuencia de la praxeología o ciencias de la acción humana:

a. La eficiencia dinámica está indisolublemente unida al concepto de función empresarial la que siempre genera información nueva de tipo práctico que antes no tenía un actor, dispersa al estar diseminado en las mentes de los seres humanos y tácita pues es difícilmente articulable de manera formal.

b. Esa función es esencialmente creativa, es decir al haber un desajuste social u oportunidad en el mercado se plasma en una oportunidad de ganancia que antes pasaba inadvertida y que cada vez un nuevo emprendedor la descubre y aprovecha.

c. La función empresarial transmite información por medio de los precios, los que transmiten información de manera muy potente.

d. Es coordinadora pues los actores empresariales aprenden a coordinar y disciplinarse en función de las necesidades del otro.

e. La función empresarial es competitiva en el sentido de que una vez que es creada y descubierta y aprovechada por la oportunidad de ganancia de un empresario, esa misma ya no puede ser creada y aprovechada por otro empresario. Hay que recordar que el proceso de mercado con empresas formadas por seres humanos de carne y hueso es de "rivalidad entre dos o más personas que aspiran a obtener la misma cosa... situación de las empresas que rivalizan en un mercado ofreciendo o demandando un mismo producto o servicio" (RAE, 2020).

f. Este proceso descrito jamás se detiene o agota, pues el acto empresarial crea nueva información que a su vez modifica en el mercado la percepción de fines y medios de los actores implicados, lo cual da lugar a la aparición de nuevos desajustes, que a su vez tienden a ser descubiertos y coordinados empresarialmente y así sucesivamente a lo largo de un proceso que jamás se detiene, donde no hay límite al conocimiento y descubrimiento de los recursos, apoyado sobre un crecimiento de la población y que tiende a ser tan coordinado como sea posible en cada momento y en cada circunstancia histórica. 
Se concluye entonces que en un sentido dinámico todo un sistema económico será tanto más eficiente conforme cada ser humano, empresa, fïma, organización e institución impulsen la creatividad y la coordinación. Entonces la dimensión dinámica de la eficiencia es más relevante que la definición estática que está presente en el maistream de la economía, a saber "maximización de la satisfacción de necesidades sometida a restricciones de recursos y tecnología", (The New Palgrave Economics Dictionary, 1987), pues todos los individuos de una sociedad salen ganando si la creatividad empresarial está moviendo todo el tiempo las posibilidades máximas de producción, tras un descubrimiento de nuevos fines y medios que previamente ni siquiera podían ser concebidos por nadie. Y prosigue Huerta de Soto (2014):

Ahora bien, requerimos una condición necesaria y suficiente para que la eficiencia dinámica prospere: como cada ser humano es una actor creativo y coordinador se requiere un axioma apodíctico de que todo ser humano tiene derecho a apropiarse de los resultados de su creatividad empresarial...si no pudiera apropiarse de lo que crea o descube se bloqueará la oportunidad de detectar oportunidades de ganancia y desaparecerá el incentivo que tiene cada ser humano para llevar adelante sus acciones. Las características de esta dinámica son que, si alguien crea algo de la nada, tiende a apropiarse de aquello que ha sido creado por él, pues no está perjudicando a nadie. En segundo lugar, cualquier resultado de la creatividad humana no existía antes de ser descubierto empresarialmente, por lo que su apropiación no puede perjudicar a nadie. En este punto es necesario anotar, que ciertas acciones coactivas y de expoliación pueden parecer empresariales, pero no lo son, pues atentan contra la libertad y propiedad privada y más bien son parte de acciones humanas interventoras y descoordinadoras, por tanto, el tipo de acciones violentas que impiden el avance de la civilización.

Concluye Huerta de Soto que concebida entonces así la economía como un proceso dinámico de tipo empresarial, la sociedad justa será aquella que de manera enérgica promueva la creatividad empresarial para que cada ser humano pueda tener la seguridad a priori de que podrá apropiarse de los resultados de su acto empresarial y que estos no serán expropiados total o parcialmente, menos aún por el Estado, institución que debe estar ahí para proteger el derecho de propiedad de cada individuo; es decir, mientras el Estado más se aparte de esta premisa, más obstáculos pondrá a la eficiencia dinámica.

Y sigue: por tanto, bloquear de alguna manera la libertad de un individuo no solo destruye la eficiencia dinámica, sino que es éticamente reprobable por irse contra la naturaleza creativa de cada ser humano, al menoscabar el derecho de propiedad. No solo es ineficiente, sino adicionalmente inmoral pues tal coacción impide que el actor desarrolle lo que por naturaleza le es propio al ser humano de carne y hueso, es decir su capacidad para crear y concebir nuevos fines... por tanto en general toda forma de intervencionismo coactiva y arbitraria en la economía por parte de un órgano estatal es dañina al avance de la civilización. Por lo dicho, la oposición entre eficiencia y equidad es falsa, pues vista desde la perspectiva de la eficiencia dinámica, eficiencia y equidad son dos caras de la misma moneda. (p.p. 20-32)

Mankiw (2015) en su popular texto de Principios de Economía, al hablar de que las personas se enfrentan a disyuntivas, lo cual es un acierto bajo el principio del costo de oportunidad, ha separado la equidad de la eficiencia, pues considera que la primera esta fuera del campo de la economía y cree más bien que está en el campo de la filosofía política. (p.5) 
Como estamos revisando, una completa definición sobre la acción humana y la función empresarial que explícitamente toma en cuenta los trabajos de Mises, Hayek, Rothbard $(2011,2015)$ y Kirzner $(1996,1998)$ la encontramos en la obra de Jesús Huerta de Soto, que como bien la ha sintetizado Leonardo Ravier (2016) según el resumen de su capítulo 16, que lo presentamos de la siguiente manera:

La acción humana y su función empresarial la ejerce el ser humano creativamente para la coordinación social bajo los principios fundamentales del derecho. Mises (2011), afirma que toda acción humana es individual, consciente y racional para alcanzar un fin, meta u objetivo a través de los medios. La acción humana le permite al individuo actuar, mejorar su estado actual de insatisfacción y sustituirlo por un estado de mejor satisfacción. El malestar es el incentivo que le permite al individuo actuar.

Por tanto, la sinergasia, que es parte de la praxeología y la teoría de la eficiencia dinámica se sustenta en lo siguiente, tal cual lo va concluyendo Leonardo Ravier:

1. La Función Empresarial es sinónimo de Acción Humana.

2. Todo ser humano actúa y ejerce la función empresarial buscando superar las situaciones de escasez, o lo que es lo mismo, buscando conseguir beneficios que le permitan satisfacer sus necesidades y pasar de un estado de menor satisfacción a un estado de mayor satisfacción en el futuro.

3. Toda acción se realiza en el tiempo entendido de manera subjetiva.

4. El presente subjetivo del ser humano supone una fundamental ignorancia inerradicable a la hora de tomar decisiones por lo que resulta imprescindible el ejercicio del aprendizaje por medio de la razón tras el ejercicio de prueba y error.

5. El futuro subjetivo del ser humano está abierto y supone una incertidumbre inerradicable respecto de los posibles resultados de sus acciones para conseguir sus fines.

6. Todo ser humano en el ejercicio de la empresarialidad traza de un plan de acción como un resultado autoevidente de un acto personal de voluntad con el objeto último de conseguir sus fines.

7. Todo ser humano en el ejercicio de la empresarialidad crea o descubre medios escogiendo los que subjetivamente considera adecuados para conseguir sus fines y rechaza todos los demás.

8. Todo individuo considera subjetivamente fin a todo aquello que considera importante y que lo pretende alcanzar. El fin para cada persona es único, solo cuando coincide, ayuda a la sinergia de la firma.

9. Todo individuo escoge los fines más importantes para él y deja de lado lo menos importante

10. Todo acto o ejercicio de la función empresarial supone una relación de valores subjetivos, psíquicamente más o menos intensos que determinan el valor, la utilidad, beneficios o sea los aciertos o ganancias y las pérdidas o costos, o errores, como resultado de sus acciones. 
Estamos de una manera ágil llegando a la sinergasia o teoría praxeológica de la firma conforme al trabajo original de Ravier (2016), la que se puede resumir en los siguientes diez principios:

Primer principio: de la Función Empresarial como sinónimo de la acción humana, bajo los principios del derecho:

1. a. Todo ser humano es motivado a la acción por la realidad de escasez y/o el deseo del beneficio. Esta escasez no está dada, aparece conforme se desarrollan nuevas necesidades que se descubren como parte de la interacción fines-medios.

1. b. Todo ser humano actúa en función de sus percepciones subjetivas e individuales con el fin de mejorar su situación actual de insatisfacción con el objetivo de pasar a una situación futura de mayor satisfacción.

1. c. Todo ser humano es dueño de su vida, por tanto, de su cuerpo, de su mente, de su conciencia y de sus creaciones.

1. d. Como la función empresarial es alterada por la presencia de otros seres humanos surge la necesidad de la inter-coordinación, la que requiere normas de interacción, por tanto, la función empresarial además de creativa es coordinadora y se enmarca en los principios generales del derecho.

1. f. La función empresarial se diferencia de las acciones invasoras e interventoras del Estado o gobierno, que son las que se realizan estas sí, bajo un concepto de explotación del hombre sobre el hombre, las que a pesar de ser creativas y especulativas, no deben ser confundidas como función empresarial. Por esto es que en nuestra visión es imposible la existencia de empresas públicas, las que deben ser consideradas como psudoempresas.

Segundo principio: De asociación o combinación creativo - coordinador:

2. a. Todo individuo que ejerce la explotación de la naturaleza se constituye como fuerza impulsora de todo el proceso de mercado en su capacidad de asociación o combinación creativo - coordinador.

2. b. El ser humano crea por asociación como potencia intelectual de la mente o por combinación material y física. Este acto es creativo y se lo hace de una manera hasta entonces no realizada, dando por resultado la creación de algo nuevo.

2. c. El ser humano coordina por asociación entre necesidades y satisfacciones tanto propias como ajenas.

2. d. Toda nueva asociación o combinación realizada por el ser humano, abre nuevos campos del conocimiento disponible y transmisible a lo largo del tejido social, por tanto, su capacidad creativo coordinadora es inagotable.

2. e. El intercambio de orden inferior es la compra y venta de bienes de consumo.

Tercer principio: De la organización de la firma como asociación humana que constituye una institución fundamental del mercado y por tanto de la sociedad: 
3. a. Las limitaciones humanas de razonamiento, conocimiento, aprendizaje y acción constituyen la razón por la cual la cooperación asociativa lleva a crear organizaciones o firmas que son parte del mercado. Se entiende que pueden ser formales o informales.

3. b. La firma surge de la asociación voluntaria entre al menos dos individuos que se proponen perseguir un mismo fin, usando en forma complementaria los medios para procurar conseguir beneficios individuales, que lleven a las partes a una situación de mayor satisfacción o beneficio simultáneamente.

3. c. Desde la teoría Hayekiana de los órdenes espontáneos (Hayek, 2006) y Smith (1983) en su Investigación de la naturaleza y causas de la Riqueza de la Naciones, se considera que las firmas son instituciones sociales que forman parte del orden del mercado, al igual que el lenguaje, el derecho, la moneda, etc.

Cuarto Principio: Del factor productivo del trabajo y el capital como unidad de servicio de la capacidad de asociación o combinación creativo coordinadora a través de la división del conocimiento:

4. a. Los bienes del capital y trabajo son indivisibles (quiere decir que no deben separarse como lo hace el mainstream y el marxismo) al ofrecer unidades de servicio o bienes, que se pueden intercambiar en el mercado.

4. b. Por medio de la división del conocimiento se intercambian unidades de servicio de capacidad de asociación y/o combinación creativo coordinadora a través del trabajo y capital siendo esta última el resultado de la primera, una combinación del trabajo con los recursos naturales.

Quinto Principio: Del intercambio de orden superior simple y asociativo:

5. a. Los intercambios de orden superior simples implican la compra y venta de bienes de capital entre organizaciones, mientras que el intercambio de orden inferior es la compra y venta de bienes de consumo.

5. b. En el intercambio de orden superior asociativo, las personas cooperan asociando las unidades de servicio que se ofrecen mutuamente como un mecanismo de intercambio de medios de producción el cual explica la mayoría de los intercambios del mercado.

5. c. Estos últimos intercambios señalados crean una relación directa entre economías capital intensivas y es la que tiene lugar en las grandes firmas, las que interactúan intercambiando materias primas, equipos, maquinaria, herramientas, repuestos.

Sexto Principio: De la universalidad de la distribución funcional de la acción humana incluido el capitalismo puro, como intrínseco de la propia naturaleza humana:

6. a. Todo ser humano ejerce la función del capitalista, la cual no es una elección, pues forma parte de la propia naturaleza humana. El capital humano es la combinación del cuerpo humano como parte del factor tierra con la capacidad de asociación creativo coordinadora del trabajo. Por lo que se explicó, jamás debe dividirse como capital y trabajo, por ser un concepto falaz. 
Séptimo Principio: El principio económico del capital humano como una unidad de cuerpo y mente:

7. a. Todos los seres humanos son capitalistas, no solo por su predisposición al ahorro, sino porque el capital forma parte de la naturaleza humana. Los seres humanos somos energía y materia combinada por tanto el ser, hacer y poseer es indivisible.

7. b. Si la propiedad privada de los medios de producción es intrínseca a la naturaleza humana, la imposición de un sistema diferente desde la coerción es contra natura e inmoral.

7. c. La capacidad productiva de un individuo es insignificante frente a la de un conjunto de individuos que ahorran y realizan intercambios de orden superior asociativo constituyendo organizaciones que aumentan sus niveles de capital, lo que explica la razón de ser de las firmas.

Octavo Principio: El principio de la jerarquía natural:

8. a. Los individuos actúan según sus escalas subjetivas y ordinales de valor. Por tanto, el concepto de jerarquía es natural e intrínseco al propio actuar individual. Las jerarquías organizacionales son una extensión o proyección de las jerarquías determinadas por las prioridades, es decir la valoración sobre medios y fines. 8. b. La delegación de tareas empresariales secundarias es causa de jerarquías empresariales, las que a su vez son expresión o proyección externa de la escala subjetiva de valores que el órgano rector de una firma manifiesta sobre sus prioridades y el orden necesario para alcanzar los fines propuestos.

Noveno Principio: El principio de las limitaciones naturales de las firmas:

9. a. El crecimiento de una organización está limitado por la carencia de precios de mercado, lo que le imposibilita de tomar decisiones eficientes. En un caso debido a la imposibilidad del cálculo económico y en otro caso debido al conocimiento disperso. Tenemos el caso de las deseconomías de escala.

9. b. Por otra parte, hay una necesidad continua de mayor eficiencia que sostiene y expresa una capacidad de asociación o combinación creativo coordinadora imprescindible para que una organización crezca hasta conseguir hacerse, hipotéticamente, con un sector específico del mercado, o con todo el mercado en su máxima extensión, logrando economías de escala.

Décimo Principio: El principio de la función organizacional y el papel de las firmas en el proceso de mercado puro:

10. a La función organizacional es aquella en que dos o más individuos cooperan a través de intercambios de orden superior asociativo con el fin de aumentar la eficiencia dinámica de la función empresarial, como fuerza impulsora de todo proceso de mercado. Se expresa desde la potencia intelectual de la mente hacia los recursos naturales en toda su extensión. 
10. b Dicha capacidad de asociación o combinación es fundamentalmente creativa con posibilidades ilimitadas en su desarrollo y expansión lo que en sintonía con la teoría de la eficiencia dinámica cada nueva asociación o combinación altera la estructura productiva existente y abre nuevas posibilidades de asociación o combinación creativocoordinadoras en un proceso de expansión del conocimiento y su materialización que nunca se acaba, una especie de big-bang social como lo denomina Huerta de Soto, o como lo tituló y desarrolló Schumpeter (1983) a su capítulo 7, "El proceso de la destrucción creadora", un protoaustriaco que fuera compañero de Mises en la universidad, pero que finalmente se desvió de la escuela austriaca cuando trabajó en Harvard con el enfoque neoclásico.

Ya que las firmas en un mercado se caracterizan fundamentalmente por hacer frente a las limitaciones humanas, asociar o combinar de manera cada vez más eficientemente los recursos para satisfacer mayores y mejores necesidades, ser un vehículo que potencia la fuerza impulsora de los procesos de mercado de una manera inagotable que mejora la calidad de vida y el desarrollo de la civilización y estar auto limitadas en función de su capacidad de lograr el éxito o acierto para mantenerse, se concluye que el único entorno coherente, eficiente y ético para su desenvolvimiento es el libre mercado puro o anarquía del mercado.

Por tanto, toda coacción al natural o innato ejercicio humano de la asociación o combinación creativo coordinadora implica un atentado contra la propia naturaleza humana y su potencial civilizador. Así concluye Leonardo Ravier (p.p. 599-625)

Landoni, (2015) en su capítulo 3 sobre "Función empresarial e instituciones", según lo resumo a continuación ha indicado que sería imposible la vida en sociedad si no existirían las reglas, obligándonos a mantener ciertas conductas a la hora de actuar. Manifiesta que algunas instituciones intervencionistas promueven una empresarialidad improductiva o pseudo empresarialidad. Indica que, si los individuos tratan de obtener bienes por vía violenta, los demás perderían los incentivos para producir pasando a un estado de improductividad. Lo único que nos asegura que eso no suceda es el establecimiento de una sociedad contractual, estable, que impida en todo momento atentar contra la propiedad privada y la libertad económica.

Landoni, (2016) manifiesta que el establecimiento firme de derechos de propiedad es un incentivo para la cooperación que siempre está presente en la función empresarial. Si hay estabilidad de estas reglas es posible la ejecución del plan empresarial y por tanto el crecimiento y ulterior desarrollo de la economía hacia el bienestar de todos y cada uno de los individuos de la sociedad, debido al ahorro, la inversión y por tanto una permanente capitalización. Esto impediría la especulación cortoplacista como única forma de empresarialidad, tan propia de ambientes inestables, intervenidos y corruptos.

La conclusión parcial de esta sección indica que una economía con multiplicidad de descubrimientos empresariales, que eleva la intensidad de capital y la capacidad para explotar economías de escala, requiere estabilidad institucional para reducir incertidumbre. Más precisamente, la economía necesita instituciones estables de economía de mercado. De lo contrario, se quedará estancada en la economía de negocios de baja productividad y escala, que 
atienden a mercados domésticos y son incapaces de alcanzar mercados de mayor volumen. (Landoni, 2015, p.p.109-163)

\section{Resultados}

El subjetivismo metodológico de la escuela austriaca es apodíctico, axiomático y deductivo, por tanto, en el que se hacen aseveraciones praxeológicas como las resumidas en la fundamentación teórica, las que como hemos visto, no presentan formulaciones matemáticas, ni estadísticas, ni evidencias empíricas, que al fin al cabo solo son historia y no sirven para efectuar predicciones cuantitativas, por cuanto la mayor parte de las veces no coinciden con la realidad, por la simple razón de que todo ser humano se enfrenta a la incertidumbre inerradicable, pues si no fuera así, seríamos seres capaces de predecir el futuro, esto haría revelarnos contra la propia naturaleza humana, que no sabe y nunca podrá saber lo que pasará en el futuro. Por lo mismo, el ser humano solo puede especular, es decir mirar con hondura, reflexionar con profundidad y eventualmente como lo ha manifestado Kirzner, (1996), con perspicacia o con serendipia, por prueba y error, acertar en sus propósitos empresariales para alcanzar sus fines y cuando se lo hace en grupo, le llevan a construir una firma, formal o informal, pero en donde al menos dos personas han coincidido en apoyarse mutuamente persiguiendo objetivos parecidos o similares.

Aunque en la enseñanza del mundo de los negocios, es decir de la administración de empresas o en la versión europea lo que se ha dado en llamar la economía de la empresa, penosamente se ha instalado una visión igualmente neoclásica, ingenieril y tayloriana como lo diría Huerta de Soto, (2010), siempre encontraremos con el método hipotético deductivo y el constructivismo, el empirismo, todo con el ánimo de formar expertos en management, algunos en los últimos tiempos están tratando de lograr formar emprendedores, (Morillo, 2019), es decir unos técnicos en artes de la empresa y por tanto de la firma, en los que el conocimiento de casos y afirmaciones normativas, sirven para darse cuenta de buenas ideas que eventualmente pueden tratar de ser copiadas o replicadas, (adoptadas y adaptadas) pero que a la hora de dar frutos, patentarán las propias ideas de cada empresario, por tanto del razonamiento, conocimiento tácito, irrepetible, difícil de transmitir, de cada ser humano. Lo que nos lleva a concluir que, en la mayor parte de las veces, por no decir en la totalidad, los bienes o servicios se parecen, pero casi nunca son idénticos y ahí está el prodigio de la empresarialidad, la que hace crear productos y servicios únicos e innovadores.

Con esta visión pasamos entonces a mirar con ojos de historiadores lo que hemos visto en estos primeros seis meses de la pandemia del COVID19 ${ }^{1}$; pues, mucha gente dándose cuenta de lo que hemos vivido en estos seis meses se adaptó con resiliencia y ha dado rienda suelta a su creatividad, así tenemos:

\footnotetext{
${ }^{1}$ La Organización Mundial de la Salud anunció el 11 de febrero de 2020 que COVID-19 sería el nombre oficial de la enfermedad. El nombre es un acrónimo de coronavirus dícese 2019 (enfermedad por coronavirus 2019, en español). Está enfermedad ha provocado la destrucción del empleo y de millones de negocios, por lo que las estadísticas están reflejando una caída importante del ingreso per cápita en la casi totalidad de países.
} 
- Telemedicina, en la mayor parte de los casos cuando se trata de eventos ambulatorios está dando excelentes resultados, incluso muy económicos, que empiezan a generar en los pacientes lealtad al médico.

- Atención médica a domicilio, como fue en el pasado.

- Servicio de compras en línea y a domicilio; aun cuando ya se daba este tipo de servicio, se ha profundizado y han aparecido muchas cadenas y formas creativas de atención personalizada, aprovechando las tecnologías de comunicación e información TIC's. Las compras típicas con de comida, abarrotes y productos farmacéuticos y otros.

- Confección de ropa cómoda para el desarrollo de teletrabajo en casa.

- Fabricación y venta de bicicletas y otras formas de locomoción, incluso de tipo eléctrico aprovechando una caída importante del tráfico en las grandes ciudades

- Confección de mascarillas.

- Confección de trajes de bioseguridad.

- Educación en línea profundizada y a todos los niveles.

- Servicios de instalación y mantenimiento de internet vía fibra óptica y satelital.

- Arriendos de casas privadas en la playa para mantener el distanciamiento social.

- Profundización de productos financieros relacionados con ahorro y crédito.

- Incremento de producción y ventas de bienes de ferretería, construcción, herramientas de bricolage. Mucha gente se ha dedicado a efectuar arreglos en sus casas que normalmente se venían postergando.

- Incremento de venta de frutas y hortalizas directamente en los hogares.

- Entrega de alimentos a domicilio.

- Entrega de artículo de bazar y papelería.

- Atención de cuidado personal de tipo estético a domicilio.

- Fabricación y comercialización de medicamentos, especialmente el paracetamol y acetaminofén

- Fabricación y comercialización de muchos tipos de desinfectantes y guantes, en líquido y geles, para manos, cuerpo y áreas sensibles como hospitales, clínicas, centros comerciales, etc.

En todos los casos, se han creado una serie de actividades económicas conexas que implican, importación, compra de maquinaria y equipo, materias primas, repuestos y sobre todo la generación de empleo para emprendimiento de transporte, embalaje y logística de todo tipo. Pero también según lo señalamos, las actividades interventoras del Estado, debido a las excesivas restricciones destruyeron e impidieron que actividades como el servicio de transporte mediante el uso de aplicaciones como Uber y Cabify, al prohibir el uso de automóviles según el número de placa, lo cual terminó con el empleo de algunos miles de personas que redondeaban su ingreso con esta actividad.

\section{Conclusiones}

Dado que cada ser humano y siguiendo a Ravier, (2016) es diferente pues dispone de cualidades, capacidades, y conocimientos únicos, es que cada individuo disfruta de la actividad generadora de beneficios en la acción; para su propio beneficio. Por ello; la teoría praxeológica de la firma se encuentra inserta entre la intersección de la ciencia de la acción humana - 
praxeología y la ciencia del intercambio -cataláctica y conforman en sí el estudio de la sinergasia; que es la ciencia de la asociación humana; esto se explica al ejemplificar a las organizaciones y / o firmas; como surgen y cuál es su funcionamiento dentro del mercado y la sociedad las que se construyen en y desde la acción humana individual y cooperativa y bajo un tipo específico de interacción más complejo que el simple intercambio unilateral que se genera entre dos personas.

Este intercambio radica en el deseo de mejorar las propias condiciones materiales de cada persona que interactúa y tiene lugar a través de sacrificios individuales que compensan el vivir en sociedad, resultando en cooperación humana y por tanto el incremento de la productividad. En todo intercambio se valora en menos lo que se da respecto de lo que se recibe; y es a través de estos intercambios voluntarios y cooperativos los que permiten determinar comprensivamente, cuál es la acción más idónea para suprimir el estado de malestar.

Al hablar de empresarios, capitalistas, empleados y consumidores, es referirse a categorías catalácticas, es decir, funciones distribuidas que ejercen todos los individuos en el mercado y donde todos y cada uno de ellos son en sentido estricto empresarios, es decir, ejercen una función empresarial en el mercado.

Al relacionar la función empresarial en el mercado; diremos que es un sistema de cooperación voluntaria exenta de coerción, a través de dicha interacción el empresario que actúa le interesa aprovechar del mejor modo posible los medios de que dispone para atender las futuras necesidades. Ni interpreta ni enjuicia las situaciones con que tropieza, solo se limita a ordenar los medios para alcanzar su beneficio.

En concordancia con la función empresarial; nace la estructura de la jerarquía empresarial que se aprecia en la firma; como la función directiva y gerencial, que es natural y producto de la proyección o extensión y materialización de la escala de prioridades que se constituyen en acciones concretas para dar orden y sentido a la producción y mejorar el bienestar de quienes interactúan. (p.p. 513-539).

Como hemos visto en el listado de actividades económicas, creativas, emprendimientos innovadores, muchas de las cuales son el semillero de futuros firmas, nacen de la propia acción humana, de su praxis, de su catalaxia y de su sinergasia. Lo único que impide esa creatividad innata en los seres humanos, son las acciones descoordinadoras e interventoras del poder estatal.

\section{Referencias bibliográficas}

Ayau, M. (2002). "Ideas esenciales del liberalismo", recuperado el 8-09-2020 de https:/ /www.youtube.com/watch?v=RtMPZAyAmxA

Benegas Lynch, A. (1986). Liberalismo para liberales, MC Ediciones, Buenos Aires. Cabezas, J. (2017). "Falla de Estado y Pérdida de Bienestar para la Sociedad", Innova Research Journal, ISSN-e 2477-9024, Vol. 2, N. 9, 1, págs. 111-120. https://doi.org/10.33890/innova.v2.n9.2017.304 
Cabezas, J. y Vásquez, C. (2017). “Desigualdad: el término más antónimo de la pobreza" Innova Research Journal 2017, Vol 2, No. 11, págs.105-112. ISSN 2477-9024. https://doi.org/10.33890/innova.v2.n11.2017.484

Constitución del Ecuador, (2008). Recuperado de https://www.oas.org/ jurídico/pdfs/mesicic 4_ecu_const.pdf.

Friedman, M. (1983). Libertad de Elegir, Ediciones Orbis, Barcelona.

González, J. (2014). Curso por internet del Introducción a la Economía del profesor Huerta de Soto, Unión Editorial, Madrid.

Eatwell, J. Murray, M. y Newman, P. (1987). The New Palgrave Dictionary of Economics, Macmillan, Londres, vol. II.

Hayek, F. (1997). Los Fundamentos de la libertad, Tomo I, Unión Editorial, Barcelona.

Hayek, F. (1997). Los Fundamentos de la libertad, Tomo II, Unión Editorial, Barcelona.

Hayek, F. (1997). "El uso del conocimiento en la sociedad”. Reis, No. 80 recuperado de https://doi.org/10.2307/40183924.

Hayek, F. (2006). Derecho, Legislación y Libertad, Una nueva formulación de los principios liberales de la justicia y de la economía política, Unión Editorial, Madrid.

Hayek, F. (2008). Camino de Servidumbre, Unión Editorial, Madrid.

Huerta de Soto, J. (2010). Socialismo, cálculo económico y función empresarial, Unión Editorial, Madrid.

Huerta de Soto, J. (2014). Ensayos de economía política, Unión Editorial, Madrid.

Huerta de Soto, J. (2016). "El paradigma neoclásico y la economía empírica" recuperado de https://www.mises.org.es/2016/05/el-paradigma-neoclasico-y-la-economia-empirica/

Kirzner, I. (1996). Creatividad, Capitalismo y Justicia Distributiva, Ediciones Folio, Barcelona.

Kirzner, I. (1998). Competencia y Empresarialidad, Unión Editorial, Madrid.

Landoni, J. (2015). Empresario Institucional, Editorial Episteme, Guatemala.

Landoni, J. (2016). "Sobre la Fuerza Motriz del Cambio Institucional. Una Perspectiva Empresarial", Revista de Instituciones, Ideas y Mercados, No(s). 64-65, Buenos Aires, pp. 121-141.

Lenin, V. (s/f) "Tres fuentes y tres partes integrantes del marxismo", recuperado el 10 de septiembre de 2020 de http: //www.izquierda.info/noticias/marxismo / Lenin Tres Fuentes y Partes. pdf

Mankiw, G. (2015). Principios de Economía, Cengage Learning, México.

Mises, L. (2011). La Acción Humana: Tratado De Economía, Unión Editorial, Madrid.

Morillo, M. (2019). Guía para Emprendedores, Emprende Ya, Editorial Mariscal, Quito.

Naciones Unidas, "Declaración Universal de Derechos Humanos", recuperado el 10 de septiembre de 2020 de https: //www.ohchr.org/EN/UDHR/ Documents/ UDHR.Translations/spn. pdf.

Nozick, R. (1991). Anarquía, Estado y utopía, Fondo de Cultura Económica, México.

RAE, "Diccionario de la real academia española de la lengua" recuperado el 8 de septiembre de 2020 de https://dle.rae.es/competencia.

Ravier, L. (2016). Historia Económica de le Empresarialidad, Hacia una Teoría Praxeológica de la Firma, Unión Editorial, Madrid.

Rothbard, M. (2011). El Hombre la Economía y El Estado, Volumen I, Unión Editorial, Madrid. Rothbard, M. (2015). Poder y Mercado, el Gobierno y la Economía, Volumen III, Unión Editorial, Madrid. 
Schumpeter, J. (1983). Capitalismo, socialismo y democracia, Tomo I, Ediciones Orbis, Barcelona.

Smith, A. (1984). La Riqueza de las Naciones, Ediciones Orbis, Barcelona. 